\title{
Pregnancy complicated by psittacosis acquired from sheep
}

\author{
R J S BEER, W P BRADFORD, R J C HART
}

\begin{abstract}
Two cases of chlamydial infection in pregnant women are described, the first serologically proved and the second suspected. In both cases the infection was probably contracted from sheep suffering with enzootic abortion. Both patients were farmers' wives who had helped their husbands with lambing and developed a non-specific febrile illness in late pregnancy. In the first case as there was no clinical improvement after 26 hours the patient was delivered by caesarean section of a live infant in good condition; the patient recovered fully. The second patient had presented a year earlier, the fetus had died in the uterus, and the patient herself died after spontaneous labour and forceps delivery 14 hours after admission. Both patients developed disseminated intravascular coagulation.
\end{abstract}

As the causal agent in enzootic abortion in ewes has a predilection for the placenta, early delivery may be the management of choice in late pregnancy if infection with this organism is suspected.

\section{Introduction}

Enzootic abortion in ewes caused by Chlamydia psittaci is common among sheep in North Devon and produces spontaneous abortion, stillbirth, or delivery of weak lambs. The condition was first reported in Scotland in 1936, and since then there have been numerous reports throughout the world to testify to its economic importance. 1 Human infection with strains of $C$ psittaci causing abortion is rare, and until recently this organism has not been considered important in obstetric practice in Britain. Roberts $e t a l^{2}$ described the first case of human abortion associated with the causal agent of enzootic abortion in ewes in the United Kingdom. We describe two cases, the first proved serologically and the second suggestive of chlamydial infection.

\section{Case reports}

CASE 1

A sheep-farmer's wife aged 34 was admitted to the maternity unit, North Devon District Hospital on 30 April 1981 at 34 weeks' gestation in her second pregnancy, having previously had a first-trimester miscarriage. She had a three-day history of a febrile illness with headache and neck, chest, and lower abdominal pain.

On examination she was feverish (temperature $39 \cdot 6^{\circ} \mathrm{C}$ ), hyperventilating, and dehydrated, with a pulse of 110 beats/minute. Apart from minimal bilateral loin tenderness there were no localising signs. A real-time ultrasound scan showed a single fetus with a biparietal diameter consistent with gestational age. Fetal cardiotocography showed a tachycardia of 190 beats/minute with normal beat-tobeat variation. Investigation on admission showed: haemoglobin

North Devon District Hospital, Barnstaple, Devon EX31 4JB

R J S BEER, PHD, MB, senior house officer in obstetrics and gynaecology (present appointment: trainee in general practice, Litchdon Surgery, Health Centre, Barnstaple, Devon)

W P BRADFORD, MRCOG, consultant obstetrician and gynaecologist

Public Health Laboratory, Exeter, Devon

R J C HART, FRCPATH, DIP BACT, director concentration $13 \mathrm{~g} / \mathrm{dl}$, white cell count $7 \cdot 2 \times 10^{\%} / 1$, with $88 \%$ neutrophils, $8 \%$ lymphocytes, and $4 \%$ monocytes. Platelet count $95 \times 10^{\%}$ (normal range $\left.150-400 \times 10^{\%} / 1\right)$, plasma fibrinogen concentration $1.96 \mathrm{~g} / 1$ (normal range $1 \cdot 5-4.0 \mathrm{~g} / 1$ ), fibrin degradation products $40 \mathrm{~g} / 1$ (normal range less than $10 \mathrm{~g} / 1$ ), activated partial thromoplastin time 43 seconds, (normal range 35-45 seconds), one-stage prothrombin time 13 seconds (normal range 11-14 seconds), suggesting mild disseminated intravascular coagulation. Blood urea, electrolytes, and glucose concentrations and findings on chest radiograph, electrocardiogram, and urine microscopy were all normal. Cultures of blood and urine were sterile. Arterial blood gas analysis showed a mild compensated respiratory acidosis.

An initial diagnosis of septicaemia was made and intravenous cephradine $500 \mathrm{mg}$ six-hourly and gentamicin $80 \mathrm{mg}$ eight-hourly was started. Shortly after admission, further discussion with the patient revealed that she had recently been in close contact with sheep suffering from enzootic abortion, and to cover the possibility of $C$ psittaci infection we also gave the patient erythromycin $100 \mathrm{mg}$ intramuscularly every six hours. Further blood coagulation studies over the next 16 hours showed a progressive fall in the platelet count to $58 \times 10^{\%} / 1$ with plasma fibrinogen concentration of $2 \cdot 27 \mathrm{~g} / 1$ and fibrin degradation products $30 \mathrm{~g} / \mathrm{l}$. A bone-marrow biopsy specimen showed plentiful megakaryocytes, suggesting increased peripheral consumption of platelets.

After 26 hours there was no clinical improvement; the patient remained feverish at $40^{\circ} \mathrm{C}$ with air hunger, and the fetus maintained its tachycardia. The patient was then delivered by lower-segment caesarean section of a live boy in good condition weighing $2490 \mathrm{~g}$. The operation was covered by an infusion of eight units of platelet concentrate. There was no retroplacental clot and good haemostasis was maintained. A heparin infusion of 20000 units daily was started immediately after operation and the patient was nursed initially in the intensive care unit. Twenty-four hours after delivery the patient's condition was normal and results of subsequent coagulation studies were normal within seven days. There were no neonatal problems.

\section{CASE 2}

A 34-year-old primigravid wife of a sheep farmer was admitted to the maternity unit, North Devon District Hospital on 17 March 1980, at 36 weeks' gestation. She was complaining of vomiting, headache, and lower abdominal pain. For the previous $\mathbf{4 8}$ hours she had felt generally unwell and fetal movements had diminished appreciably. For the previous few weeks the patient had been fit enough to help with the lambing on her husband's farm.

On admission she was feverish (temperature of $38.5^{\circ} \mathrm{C}$ ) and mildly dehydrated and had slight bilateral loin tenderness. A real-time ultrasound scan showed a single fetus with a biparietal diameter consistent with dates. Fetal heart echoes were normal.

Initially acute pyelonephritis was diagnosed and intravenous treatment was started with fluids and ampicillin $500 \mathrm{mg}$ six-hourly, to which gentamicin $80 \mathrm{mg}$ eight-hourly was added six hours later as there had been no clinical improvement.

Spontaneous labour started 12 hours after admission, at which time fetal heart sounds were absent. Vaginal examination showed a dilating cervix, so the membranes were artificially ruptured, releasing clear liquor.

Two hours later the patient collapsed, becoming cyanosed with air hunger and profoundly hypotensive with a tachycardia of 140 beats/ minute. After intravenous hydrocortisone $1 \mathrm{~g}, 0.4 \mathrm{mg}$ naloxone, and $500 \mathrm{ml}$ dextran 70 a gentle occipitoanterior forceps delivery was performed under pudendal block ( $1 \%$ lignocaine), with the delivery of a stillborn infant weighing $2600 \mathrm{~g}$. There was no retroplacental clot and virtually no blood loss. Despite ergometrine $0.5 \mathrm{mg}$ given intravenously, the uterus remained flaccid so a oxytocin infusion (20 units) was started. Almost immediately after delivery, however, the patient's condition again deteriorated and cardiac arrest occurred 90 minutes after her initial collapse. Despite intensive attempts at resuscitation using external cardiac massage and endotracheal intermittent positive pressure ventilation the patient died in asystole. 
Blood coagulation results available immediately after death showed pronounced disseminated intravascular coagulation, with fibrin degradation products of $320 \mathrm{~g} / \mathrm{l}$, plasma fibrinogen concentration of $1 \cdot 1 \mathrm{~g} / \mathrm{l}$, and platelet count $11 \times 10^{9} / 1$. No organisms were grown from blood or urine on routine culture.

At necropsy there was acute non-specific reactive hepatitis with a considerable increase in neutrophils and large, rather bizarre mononuclear cells. These non-specific changes suggested an overwhelming infection. There was no evidence of amniotic embolism or acute pyelonephritis.

\section{Investigations and results}

Sera were taken from the first patient on days 3,10 , and 31 . The farm flock was also sampled in June 1981, about three months after lambing; sera were examined from four non-aborted healthy ewes and four sheep vaccinated against enzootic abortion six weeks before lambing (both groups delivering healthy lambs) and five aborted ewes. All sera were tested by complement-fixation tests using $C$ psittaci antigen (supplied by the Division of Microbiological Reagents, Central Public Health Laboratory, Colindale). The anti-complementary activity of the sheep sera was overcome by inactivating them at $60^{\circ} \mathrm{C}$; none of them reacted with normal yolk sac antigen after this treatment. All sera were tested at the Public Health Laboratory, Bristol by indirect immunofluorescence using whole inclusions of the strain of $C$ psittaci that causes enzootic abortion as antigen. $Q$ fever antibodies were not found in any of the sera. The table confirms infection in both the first patient and her farm flock.

Results of tests for antibodies to $C$ psittaci. Results expressed as reciprocal of titres

\begin{tabular}{lcc}
\hline & $\begin{array}{c}\text { Complement } \\
\text { fixation }\end{array}$ & Immunofluorescence \\
\hline Case 1: & & \\
Day 3 & 10 & $<8$ \\
Day 10 & 20 & $<8$ \\
Day 31 & 160 & 128 \\
Aborted sheep: & 80 & 512 \\
A & 20 & 1024 \\
B & 10 & 128 \\
C & 160 & 256 \\
D & 20 & 512 \\
Normal sheep: & 10 & 128 \\
F & 10 & $<8$ \\
G & 20 & $<16$ \\
H & 20 & $>1024$ \\
Vaccinated sheep: & 160 & 1024 \\
J & 40 & $>512$ \\
K & 20 & \\
L & 40 & \\
M & & \\
\hline
\end{tabular}

\section{Discussion}

Schachter $e t \mathrm{al}^{3}$ subdivided chlamydial infections of man into two groups according to their mode of transmission. Direct person-to-person contact is the route of infection in trachoma, inclusion conjunctivitis, genitourinary tract infection, and lymphogranuloma venereum. In the second group, the zoonoses, man is an accidental host usually acquiring the infection from birds, producing a pneumonic illness. Chlamydiae from domestic and wild animals, however, may also produce signs of severe systemic upset ${ }^{4}$ or simply subclinical infection; several serological surveys of people in contact with chlamydia-infected animals suggest that these animals may be the source of human infection. ${ }^{5}$

Chlamydiae have been recorded from human spontaneous abortion tissue ${ }^{6}$ and one such strain resulted in placentitis and abortion after infection of cattle with this isolate.?

Studies in Russia suggest Chlamydia is responsible for an appreciable number of spontaneous abortions and perinatal and infant deaths as well as chronic gynaecological disease. ${ }^{8}$

Both our patients were farmers' wives in late pregnancy who helped their husbands with lambing in flocks that had active infection at the time of their illnesses. The first patient showed a diagnostic rising titre of antibody by both complement-fixation and immunofluorescence tests. The high concentrations of antibody by immunofluorescence in the sera from sheep that had aborted were consistent with psittacosis. These results strongly suggest that the first patient was infected with this organism, with which she had been in close contact. Though laboratory tests for chlamydia were not carried out on the second patient the infection in the sheep and the similarity of symptoms to those of the first patient suggest that she too may have been infected with the causal agent of enzootic abortion in ewes.

Disseminated intravascular coagulation in psittacosis has been reported in non-pregnant persons ${ }^{9-11}$; the origin of the infection in these cases was avian. We report the first association between disseminated intravascular coagulation and $C$ psittaci infection in pregnancy.

The strains of Chlamydiae that cause enzootic abortion in ewes can establish placental and fetal infection in animals after chlamydaemia, with a predilection for the hilar region of the placentome. ${ }^{1}$ The first patient made no real clinical improvement despite erythromycin treatment until she was delivered. The same predilection for placental tissue may exist in humans infected with the causal agent of enzootic abortion in ewes and unless this focus of infection is removed clinical recovery may be delayed, with the risk of a stillborn fetus. If infection with the strain of $C$ psittaci that causes enzootic abortion in ewes is suspected in late pregnancy, early delivery may be the correct management, and the placenta should be examined for the organism in such cases.

The clinical picture and epidemiology in the second case makes it likely that chlamydiae were responsible for her illness and subsequent death. With hindsight, had this diagnosis been considered initially, delivery soon after admission might have saved both mother and infant.

We thank Dr C R Tribe, regional assessor to the Report on Confidential Enquiries into Maternal Deaths in England and Wales, for his histopathological report, and Miss Catherine Jennings for typing the manuscript.

\section{References}

1 Shewen PE. Chlamydial infection in animals: a review. Can Vet $\mathcal{f} 1980$; $21: 2-11$.

2 Roberts W, Grist NE, Giroud P. Human abortion associated with infection by ovine abortion agent. $\mathrm{Br}$ Med $\mathcal{F} 1967$;iv:37.

3 Schachter J, Storz J, Tarizzo ML, Bögel K. Chlamydiae as agents of human and animal diseases. Bull WHO 1973;49:443-9.

4 Giroud P. Observations et données expérimentales concernart les avortements chez l'homme et l'animal (rickettsioses, toxoplasmoses, néorickettsioses ou group psittacose). Archives de l'Institut Pasteur de Tunis $1957 ; 34: 187-206$.

5 Storz J. Chlamydia and chlamydia-induced diseases. Springfield, Illinois: Charles C Thomas, 1971.

6 Schachter J, Dawson CR. Human chlamydial infection. Littlejohn, Massachusetts: Science Group, 1978.

${ }^{7}$ Page LA, Smith PC. Placentitis and abortion in cattle inoculated with chlamydiae isolated from aborted human placental tissue. Proc Soc Exp Biol Med 1974;146:269-75.

8 Terskikh II, Dzhavad-Zade MD, Kakhramanov TB, et al. The role of chlamydia in pathological pregnancy and chronic gynaecological disease. Vopr Virusol $1977 ; 4: 484-8$.

9 Hamilton DV. Psittacosis and disseminated intravascular coagulation. Br Med F 1975;ii:370.

10 Laidlow E, Mulligan RA. Psittacosis and disseminated intravascular coagulation. Br Med $\mathcal{F} 1975 ; \mathrm{ii}: 688$.

11 Byrom NP, Walls J, Mair H. Fulminant psittacosis. Lancet 1979;i: 353-6.

(Accepted 24 February 1982)

\section{Correction}

One year's treatment with propranolol after myocardial infarction: preliminary report of Norwegian multicentre trial

The legends to figures 2 and 3 in this article (16 January, p 155) have been criticised as confusing. They should have read: FIG 2-Survival curve for sudden cardiac death (intention to treat); FIG 3-Survival curve for total death (intention to treat). 